\title{
Improving Quality Agricultural Practices in Tropical Environments through Integrated Geophysical Methods
}

\author{
DorcasS. Eyinla $^{1 *}$ and Michael A. Oladunjoye ${ }^{2}$ \\ ${ }^{I}$ Department of Earth Sciences, AdekunleAjasin University, AkungbaAkoko, Ondo State, Nigeria \\ ${ }^{2}$ Department of Geology, University of Ibadan, Ibadan, Oyo State Nigeria
}

\begin{abstract}
Often, much attention is paid to things that do not majorly "sustain life" while the main pre requisite to living is usually left unattended to. Geoscience has been a tool used in solving the Earth's challenges both directly and indirectly. For instance, mining processes as well as hydrocarbon exploration has been aided extensively by the application of Geoscience, whereas Geophysics as a branch of Geoscience, which has proven worthwhile with so much importance in solving societal major need - Agriculture, is not gaining much attention.For agricultural application of geophysical methods, the three of all methods predominantly used are Electrical resistivity, Electromagnetic induction, and Ground Penetrating Radar (GPR). All these three methods are active, requiring artificial application of energy.Electrical resistivity method measures the electrical resistance for a bulk volume of soil which lies beneath the surface. This method basically reveals the subsurface electric field produced by the artificial application of electric current into the ground. An electromagnetic induction method measures the electrical conductivity for a bulk volume of soil directly beneath the surface. An instrument called ground conductivity meter is commonly employed for shallow electromagnetic induction investigations. With the Ground-penetrating radar method, an electromagnetic radio energy pulse is directed into the subsurface, followed by measurement of the elapsed time taken by the radar signal as it travels downward from the transmitting antenna, partially reflects off a buried feature, and eventually when it returns to the surface as it is picked up by a receiver. Past research indicates a wide range of indispensable uses for these three major geophysical methods employed in agriculture. Starting from soil water content monitoring using apparent soil electrical conductivity (ECa) measurements and Soil salinity assessment obtained with electrical resistivity and electromagnetic induction methods, followed by the use of GPR for updating and improving soil survey maps. These are used to evaluate soil property spatial variation.Agricultural geophysical measurements often tend to exhibit substantial variability by measuring soil electrical conductivity, soil dielectric constant (Water Content), spatial, horizontal and vertical changes. The Soil Water Content (SWC) controls important physical, chemical and biological processes such as plant growth, solute transport, rainfall, runoff, erosion, and ultimately pedogenesis. An understanding of the spatial and temporal variability in the soil properties (precision farming) using Geophysical methods will enhance the agricultural produce as well as soil management.Agricultural geophysics is the simplest and the most rapid method of identifying the nature of soil variability in tropical environments as illustrated by some case studies.
\end{abstract}

Keywords:Agricultural Geophysics, Electrical resistivity, Electromagnetic Induction, GPR, Apparent soil electrical conductivity, Soil spatial property.

\section{Introduction}

Soil Water Content (SWC) is a key control on plant growth and health.Natural geologic processes can cause soil variations and associated water-holding capacity to vary significantly over a short or wide distances. As a consequence, a continuous and precise spatially and temporal follow-up of the soil physical and chemical properties is required in order to have maximum yield.

From a global perspective, irrigated agriculture makes an essential contribution to the food needs of the world. While only $15 \%$ of the world's farmland is irrigated, roughly 35 to $40 \%$ of the total supply of food and fiber comes from irrigated agriculture (Rhoades and Loveday, 1990). However, vast areas of irrigated land are threatened by salinization. Although accurate world wide data are not available, it is estimated that roughly half of all existing irrigation systems (totaling about 250 million ha) are affected by salinity and waterlogging (Rhoades and Loveday, 1990).

Salinity also can be a concern when streams, bores, dams and soils become more saline. In tropical region, it therefore becomes highly essential to know how much salt is present in water used for irrigation. This amount of salt in the soil will determine which crops or trees can be grown. Observed effects of soil salinity include reduced growth and performance of cereals and grain legumes, loss of clovers and medics from pastures and invasion by salt-tolerant weeds (e.g. sea-barley grass).Salinity limits water uptake by plants by reducing the osmotic potential and thus the total soil water potential. Salinity may also cause specific ion toxicity or upset the 
nutritional balance. Aside from decreasing crop yield and impacting soil hydraulics, salinity can detrimentally impact ground water, and in areas where tile drainage occurs, drainage water can become a disposal problem.

A spatially continuous survey procedure is needed to identify areas where high rates of subsurface flow will occur. Such a method is important to the development of improved field management practices to minimize offsite movement of agrochemicals in the near-surface zone.

In recent times, several techniques are adopted in carrying out research to determine the main soil parameters and their temporal variations. This procedure is generally known as Precision Farming (PF).Precision Agriculture is a growing trend combining some geospatial data sets, state of the art farm equipment technology, GIS and GPS receivers to support spatially variable field application of fertilizer, soil amendments, pesticides, and even tillage effort (Morgan and Ess, 1997). The results obtained from PF are used to exploit the farm soils in a more efficient way, thereby yielding an increase of crops without using chemical fertilizers and pesticides; thus reducing the environmental impacts on agricultural activity.In essence, precision agriculture allows a farm filed to be divided into different management zones for the overall purpose of optimizing economic benefits and environmental protection.

In agriculture, geophysics (which can be defined as the application of physical principles to studies of the Earth)has gained more applications than other geosciences.Geophysical methods have been applied to soil sciences for a considerable period of time. Garré et al., (2012) developed a methodology to measure the SWC dynamics in a cropped field while Werban et al. (2008) monitored 2-D electrical resistivity changes due to root water uptake in a $0.4 \mathrm{~m} \times 0.5 \mathrm{~m}$ plot. These recent studies open interesting perspectives in using geophysical methods for investigating the impact of Precision Farming (PF) on man and the environment at large, especially in tropical region.

\section{Review of Geophysical Methods Commonly Adopted in Agricultural Geophysics}

In order to choose the proper geophysical method for monitoring changing soil conditions, consideration must first be given to the different physical properties responded to by the various geophysical methods and then whether any of these physical properties are influenced by the soil condition of interest.Delineating a subsurface feature with geophysics requires there to be a contrast between the feature and its surroundings with respect to some physical property responded to by a geophysical method. Any of the methods selected must respond to a physical property that is in turn affected by temporal changes in soil conditions or the spatial patterns of subsurface features; otherwise, useful information cannot be obtained on these soil conditions or subsurface features of interest.

The investigation depth required and the size of the feature to be detected is two important issues that should be taken into account when deciding on the equipment to use and its setup. The three geophysical methods commonly adopted in agriculture are given in Table 1.

Table 1: Physical Properties responded to by Geophysical Methods

\begin{tabular}{|l|l|}
\hline Geophysical Method & Physical Property \\
\hline Ground-penetrating radar & Dielectric constant and electrical conductivity \\
\hline Electrical Resistivity & Electrical resistivity (or electrical conductivity) \\
\hline Electromagnetic induction & Electrical conductivity (or electrical resistivity) \\
\hline
\end{tabular}

\subsection{Use of GPR inAgriculture}

The GPR method is based on transmitting a high-frequency electromagnetic pulse signal in $\mathrm{MHz}$ (radio waves) from a transmitting antenna to the subsurface to probe lossy dielectric material and recording of the pulse responses reflected from the interfaces and objects below the earth surface, e.g. soil/bedrock interface (Annan 2002; Allred et al. 2008). The system measures the time which takes the electromagnetic energy to travel from the antenna to the interface and back.

The principle is that when an electromagnetic wave propagates through the ground and encounters a surface where the dielectric property of the ground change, part of its energy is reflected and part of it is transmitted. Some of the factors influencing dielectric properties include the type of salts in the soil water and their concentrations, the degree of water saturation, and the clay content. It is believed that material with higher conductivity rapidly reduces the signal and limits the depth of penetration.

Typically, GPR produces a time-distance record of the subsurface. The vertical scale represents the two-way travel time of the radar pulse through the subsurface. The primary effect of conductivity on electromagnetic waves is energy loss, which is expressed as the real part of the conductivity. The imaginary part contributes to energy storage and the effect is usually much less than that of energy loss. In highly conductive materials, the electromagnetic energy is lost as heat and thus the electromagnetic waves cannot propagate as deeply. Therefore, GPR is ineffective in materials such as those under saline conditions or with high clay contents (Cassidy, 2009). 
One of the sophisticated physical methods developed for non-destructive in situ measurements of measure soil water content is Time Domain Reflectometry (TDR), which has been widely used for determining soil moisture since the 1980s (Topp et al., 1980; Robinson et al., 2003). TDR measurements are invasive; the probes must be installed into soil, which may slightly alter the soil properties. GPR has the potential to overcome these problems and is considered one of the most suitable methods for monitoring soil water content during and after irrigation because GPR data acquisition is fast compared to other geophysical methods which enable measurements to be made quickly and repeatedly, yielding high temporal resolution monitoring. This feature is vital as it helps to capture rapid changes. The GPR systems are compact and easy to use compared to other geophysical methods (figure 1). This feature enables scanning over a wide area and the collection of 2D or 3D data.

Another property is that GPR response reflects the dielectric properties of soil that are closely related to its water content. It can be used as a completely non-invasive method as the antennas do not have to touch the ground and thus it does not disturb the natural soil conditions.

\subsubsection{Soil moisture determination using GPR}

There is a close relation between soil dielectric permittivity and its water content. GPR can be used to measure this proxy and the soil water content by implementing a variety of measurement and analysis techniques. They provide different sampling depths, and spatial and temporal resolutions and accuracies.

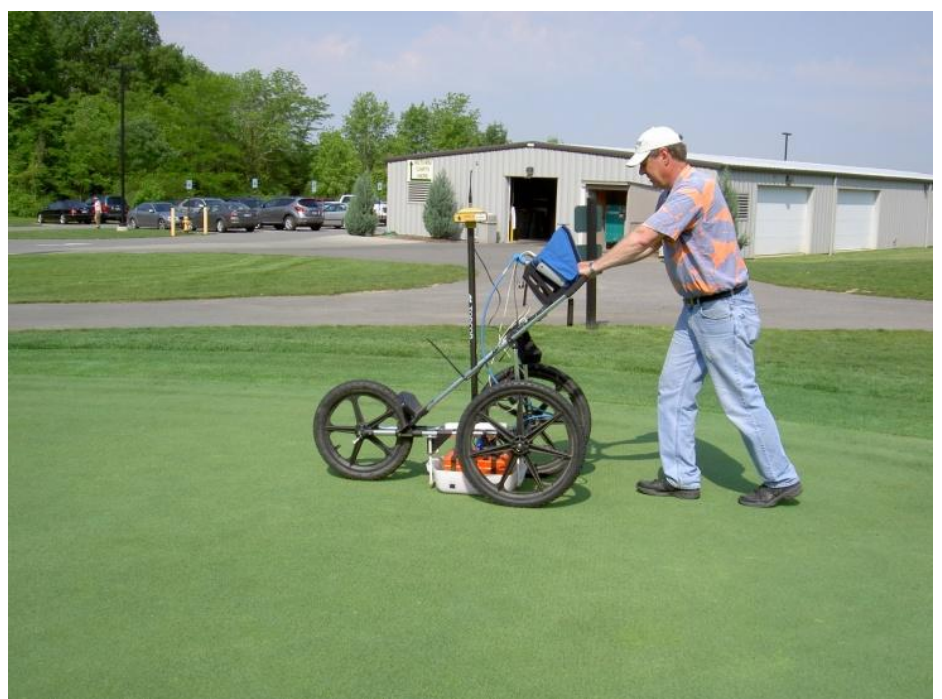

Fig. 1: Ground Penetrating Radar in use for agricultural application (Barry Allred, 2012)

\subsection{Use of Electrical Resistivity Method in Agriculture}

Electric conductivity describes the ability of a material to pass free electric charges under the influence of an applied field. Soil Electrical Conductivity (EC) is a measurement that correlates with soil properties that affect crop productivity, including soil texture, Cation Exchange Capacity (CEC), drainage conditions, organic matter level, salinity, and subsoil characteristics. The composition of a soil gives a very good indication as to what order of resistivity is to be expected. Soil resistivity measurement is normally carried out to determine the actual value for the in-situ soil under the prevailing weather conditions in which an electrode is installed. It is well known that the resistance of an earth electrode is heavily influenced by the resistivity of the soil in which it is driven and as such, soil resistivity measurements are an important parameter when designing earthing installations.

In addition to EC values separating variations in soil texture, EC has been shown to relate closely to other soil properties used to determine a field's productivity.

2.2.1 Water-holding capacity:Droughty areas typically have distinct textural differences from those with excess water; these can be identified using EC. Soils in the middle range of conductivity, which are both medium-textured and have medium water-holding capacity, may be the most productive. Since water holding capacity typically has the single greatest effect on crop yield, this is likely the most valuable use of EC measurements for Virginia. 
2.2.2 Cation Exchange Capacity (CEC):CEC is related to percent of clay and organic matter. As the percent of clay and organic matter increase, the CEC also increases. Research bears out the correlation between conductivity and CEC through its relationship to clay.

2.2.3 Depth to claypan:The response of conductivity to the presence of clay has been used to accurately predict the depth of topsoil over a clay layer or rock outcropping.

2.2.4 Porosity:The greater the total soil porosity, the more easily it conducts electricity. Soil with high clay content has more total pore space than sandier soils when other soil parameters remain constant.

2.2.5 Salinity: The early signs of soil salinity are often difficult to pick visually and a soil test is required to determine the degree of salinity.An excess of dissolved salts in the soil called salinity of a soil sample is determined by measuring its electrical conductivity. Salinity units are expressed as deci-Siemens per metre $(\mathrm{dS} / \mathrm{m})$. Information on plant tolerance is based on a soil saturated paste extract (ECe). This method is reliable and most accurately describes the salinity status of the soil but it also requires laboratory facilities to be completed properly.

2.2.6 Temperature:As temperature decreases to the freezing point of water, soil EC decreases slightly. Below freezing, soil pores become increasingly insulated from each other and overall soil EC declines rapidly(Grisso et al., 2009).

The most commonly used resistivity equipment is the Veris 3100 EC Mapping System as shown in figure 2. (Veris Technologies, Salina, Kansas).

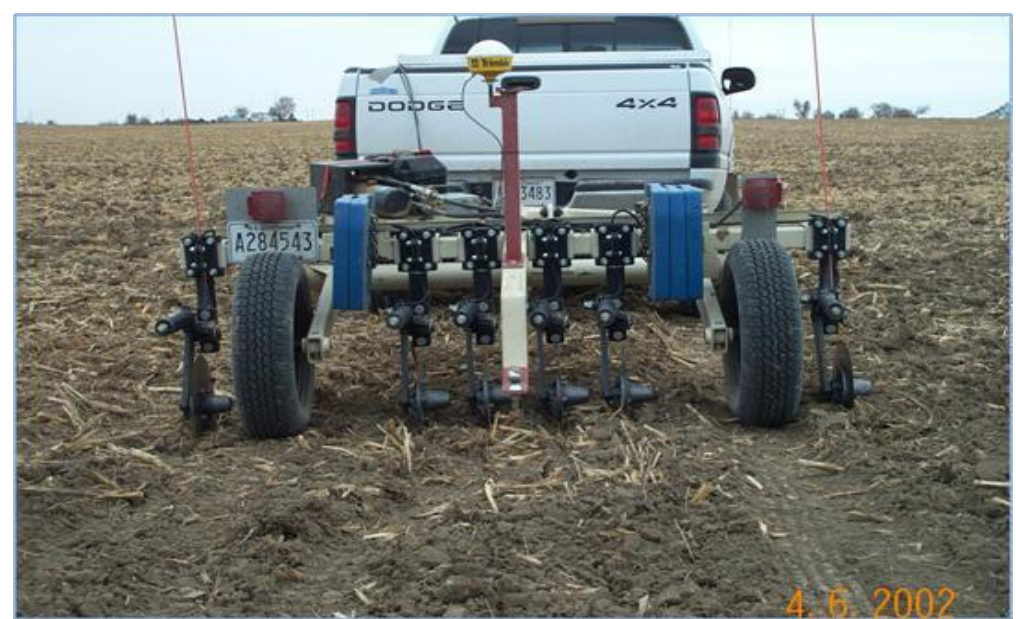

Fig. 2: Resistivty in use for agricultural application (Barry Allred, 2012)

\subsubsection{Correlation of Soil EC and Crop Yield}

As shown in figure 3, Yield maps are frequently correlated to soil EC. In many situations, these similarities are explained through differences in soil. The presence of what in the soil is what makes the material respond to electrical resistivity method. So the water-holding capacity of the soil is a major factor affecting yield. Therefore, the yield map will likely show a strong correlation to the soil EC. In general, soil EC maps may indicate areas where further exploration is needed. Most likely, soil EC maps give valuable information about soil differences and similarities and this makes it possible to divide the field into smaller management zones. Zones that have consistent EC readings are areas that have similar soil properties and can be grouped together for soil sampling and management. This can help improve the agricultural productivity of the area. 


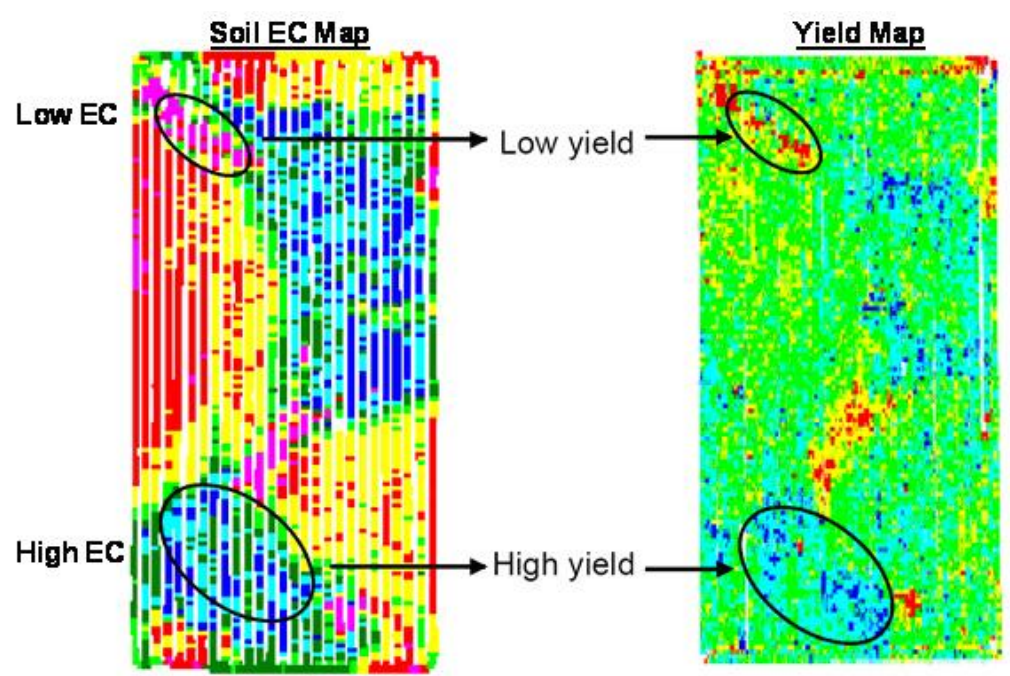

Fig. 3: Comparison between the yield map (right) and soil EC map (left). The areas of low soil EC (pink) relate to low yield (reds) as well as a high soil EC (blue) relates to high yield (blue). (Grisso et al., 2009)

\subsection{Electromagnetic Induction}

This can provide a large-scale, rapid survey before a more detailed, data-intensive GPR survey (figure 4). Electromagnetic induction is well suited in measuring salinity in soil, and many successful applications have been reported in the soil science literature. Electromagnetic induction has been used to locate buried toxic waste sites (Nyquist and Blair, 1991), to map saline areas in soils (Mankin et al., 1997) to track plumes from leaking livestock waste lagoons or feedlots (Bowling et al., 1997) and to measure the thickness of sea ice (Kovacs and Morey, 1991).Similarly, nutrients in soil, primarily from manure applications or waste sites, have been measured using EMI techniques.

In an application related to precision agriculture, Jaynes et al. (1993) investigated the use of EMI linked to a global positioning system (GPS) to map soil properties.

Dalan(1991) used two EM conductivity meters to locate buried ridge and swale topography and borrow pits in an archaeological survey in southwesternIllinois. Because EMI can be used to rapidly locate majorsubsurface variations of conductivity, geophysicists use this technology to effectively complement GPR.Electromagnetic induction should be useful to rapidly target major subsurface soil discontinuities, subsequently allowing the soil surveyor to focus on major discontinuities with detailed GPR surveys. Used in tandem and interfaced with a GPS, these two technologies have the potential to provide a soil mapping system that will provide information about areas in the soil subsurface that have a high potential for influencing subsurface, offsite movement of agrochemicals.

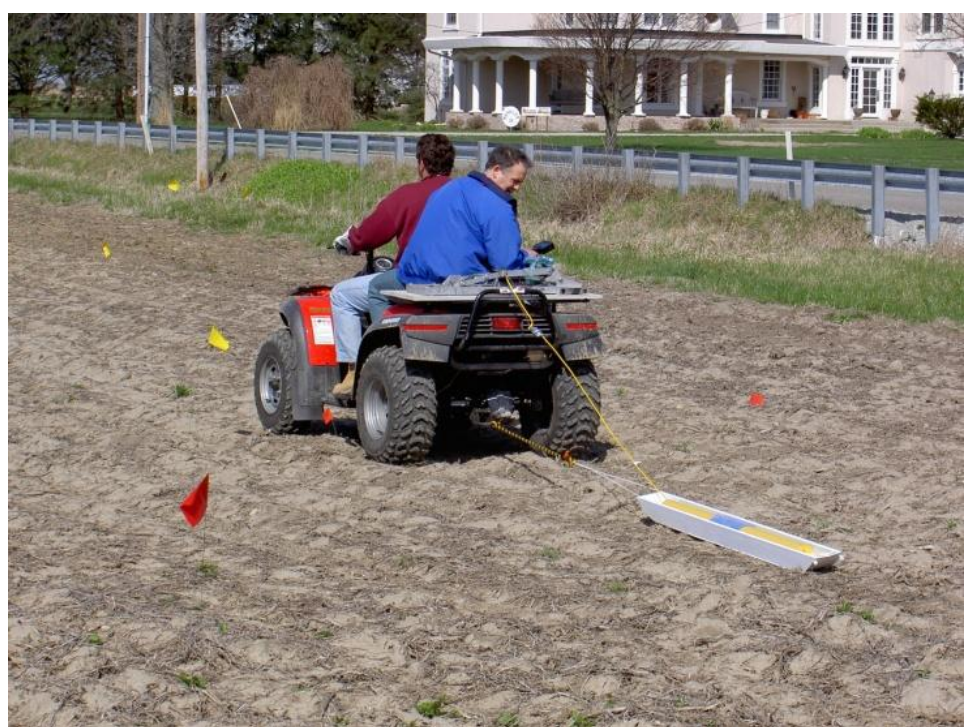

Fig. 4: Electromagnetic Induction in use for agricultural applications (Barry Allred, 2012) 


\section{Determination of Clay-pan Depth Using Electrical Resistivity Tomography}

The occurrences of clay-pans have been found to affect growth in plants especially for deep rooted types. Identification of clay-pan layer can be achieved through some geophysical methods. Most commonly, electrical resistivity imaging and electro-magnetic induction have been used in this regards (Doolittle et al, 1994; Sudduth et al, 1995). This is a non-destructive approach that covers a larger area within a short time compared to destructive methods such as pitting, coring etc. Knowing the thickness and depth to the top of claypan layer is an important factor in land management prior to planting especially where the clay-pan layer is predominant.

For this, a field scale experiment (Oladunjoye et al., 2014) was carried out to determine the effect of clay-pan thickness and depth on growth rate of plants in Ajibode area of Ibadan using electrical resistivity imaging. Field measurements were performed on a piece of land usually used for cultivation of plants e.g., cassava, maize, yam etc. The method adopted was the Wenner array in which measurements were taken at interelectrode spacings of $1 \mathrm{~m}, 2 \mathrm{~m}, 3 \mathrm{~m}, 4 \mathrm{~m}, 5 \mathrm{~m}, 6 \mathrm{~m}$ and $7 \mathrm{~m}$ respectively for each profile. A total of ten profiles were established. The measured apparent resistivity data were subjected to inversion using RES2DINV software.

The results of the investigation show that clay-pan layer usually occurs as a resistive layer at relatively shallow depth. As shown in Figures 5, 6, 7, 8 and 9, the topsoil covering the clay-pan layer ranges in thickness from $0.6-1.1 \mathrm{~m}$ while the thickness of the clay-pan itself ranges between $0.8-1.9 \mathrm{~m}$. The depth to the base of the clay-pan layer ranges between $1.9-3.0 \mathrm{~m}$. Information obtained through manual digging at some selected points show that the topsoil varies from $0.5-0.9 \mathrm{~m}$ while the thickness of the clay-pan varies from $1.0-1.6 \mathrm{~m}$ which is in good agreement with the geophysical measurements. The thickness of the clay-pan varies from place to place as depicted in the figures. The clay-pan may occur at the surface as shown in Figures 5, 8 and 9 while it may be covered by veneer of topsoil in many instances.

The results of this investigation show that only shallow rooted plants can survive in this area since there nutrients can be tapped at shallow depth. On the other hand, deep rooted plants may find it difficult to survive because of likely difficulty in their roots to penetrate the hard lateritic clay-pan layer. For shallow rooted plants to survive in such area, the thickness of the soil cover plays a significant role.

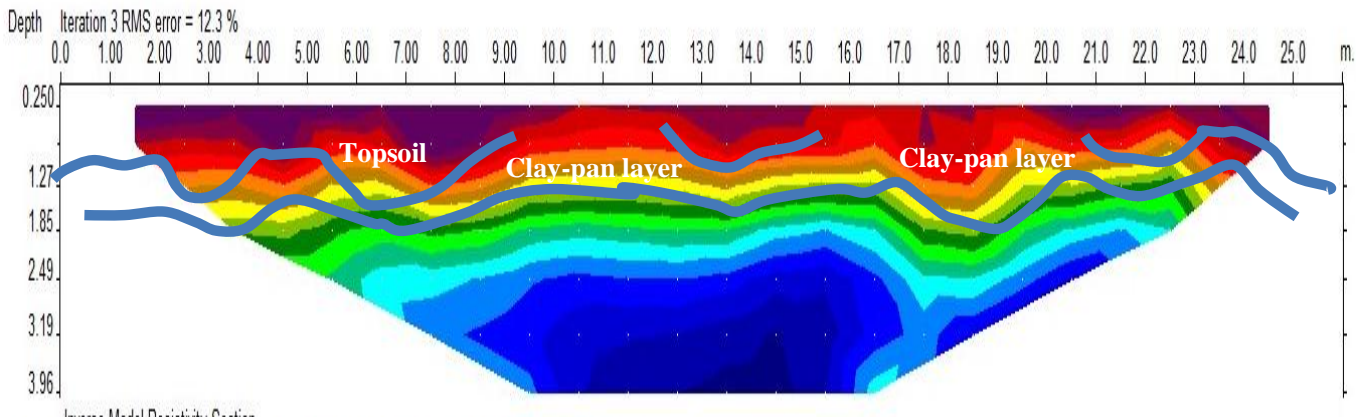

Inverse Model Resistitity Section

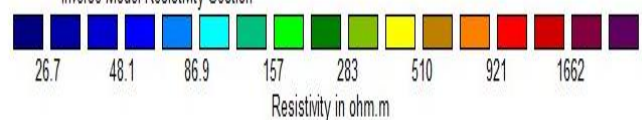

Unit electrode spacing $1.00 \mathrm{~m}$

Fig. 5: Inverted Resistivity Model for Profile 2

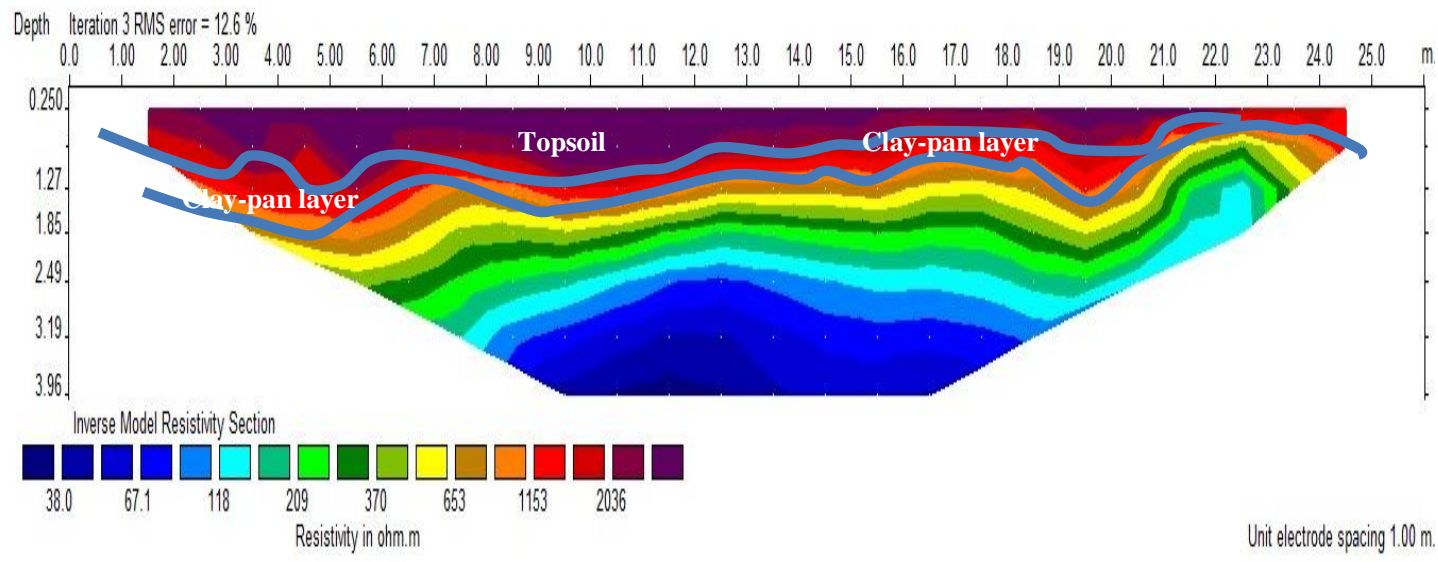

Fig. 6: Inverted Resistivity Model for Profile 4 
Depth Headion 3RUS eroo $=15.6 \%$

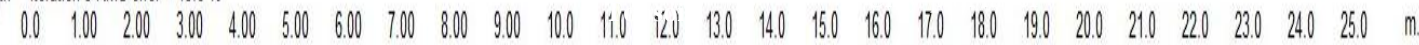

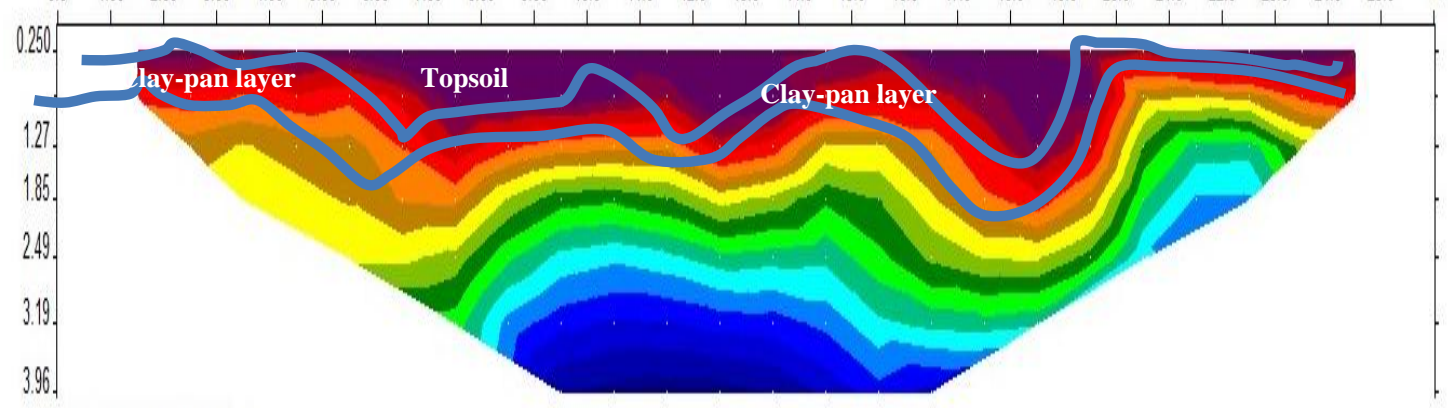

Imerse Model Resistitity Section

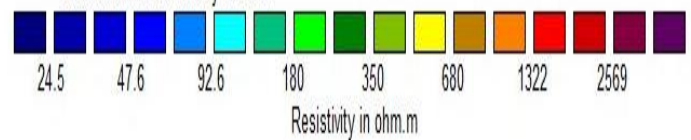

Unit lectrode spacing $1.0 \mathrm{~m}$

Fig. 7: Inverted Resistivity Model for Profile 6

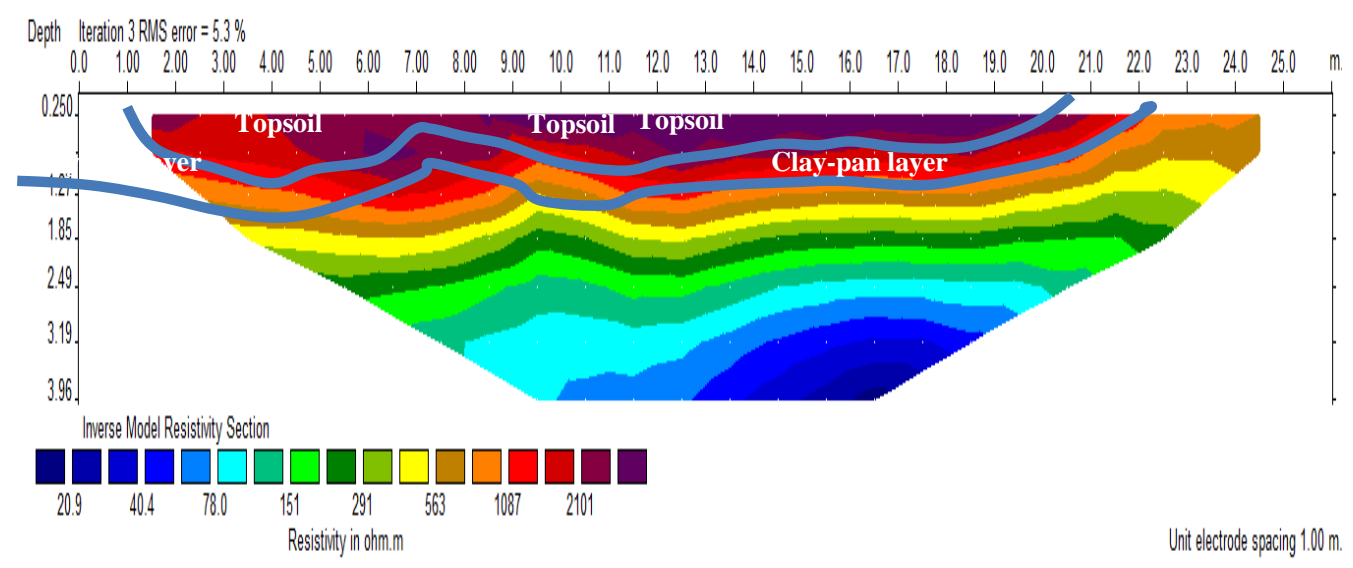

Fig. 8: Inverted Resistivity Model for Proflie 8

Deph leertion 3 PNIS erov $=4.4 \%$

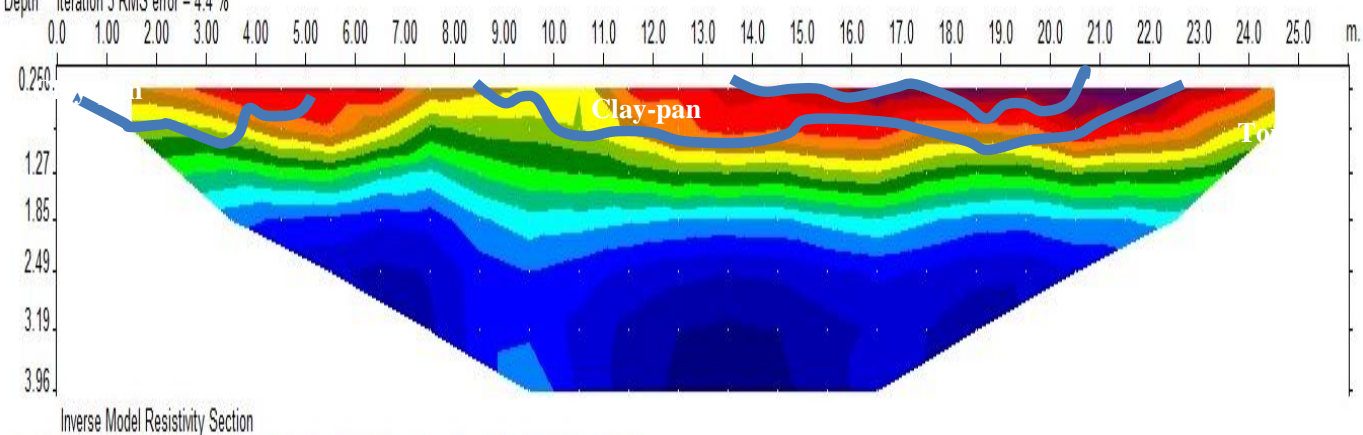

Imerese Model Resistitity Section

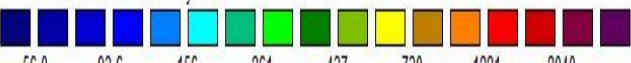

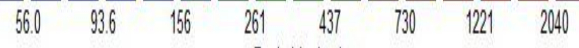

Ressisityyninom.m.m

Unit ectrode spacing $1.00 \mathrm{~m}$

Fig. 9: Inverted Resistivity Model for Proflie 10 


\section{Determination of the Relationship between Apparent Electrical Conductivity, Water Content and Growth Rate of Maize}

In this case study, Ezeoke (2014) carried out a laboratory experiment to determine the influence of soil moisture content on electrical conductivity and its relationship to the growth rate of planted maize. The research was conducted at an experimental area within University of Ibadan. A Miller 400D digital resistance meters was adopted for electrical conductivity measurements using Wenner array resistivity method on soil sample packed inside a wooden box. Measurements were taken at $10 \mathrm{~cm}, 20 \mathrm{~cm}, 30 \mathrm{~cm}, 40 \mathrm{~cm}$ and $50 \mathrm{~cm}$ apart was taken. The measured apparent- resistivity data sets were inverted by using the RES2DINV software.

As shown in Figures 10 and 11, electrical conductivity of the soil varies from point to point along each of the established profile at different electrode spacing suggesting different depth of investigation. The results of the investigation have shown that electrical conductivity of soil depends on the moisture content of the soil which helps the growth rate of the plant. It was therefore concluded that, areas with high electrical conductivity or low electrical resistivity in the box coincides with area where there were abundant moisture content, and also the maize located at this points have better growth rate than those located in the area of depleted moisture content which coincides with area of lower electrical conductivity or higher electrical resistivity as shown in Table 2. Figure 3 is a field example of the effect of apparent soil electrical conductivity on the growth rate of planted maize at University of Ibadan teaching research farm. The red arrow indicate areas where the plant is flourishing very well which is an indication of high soil electrical conductivity controlled primarily by soil moisture content among other factors. The blue arrow indicates areas with stunted growth indicating low soil electrical conductivity of the soil which is in agreement with the laboratory experiment.

\section{Determination of Drainage Pipe Using Ground Penetrating Radar (GPR)}

Figure 13 illustrates the field procedure involved in the use of Ground Penetrating Radar to detect buried drainage pipe in an agricultural farm. The result obtained is as shown in Figures 14 and 15. Each map represents radar amplitudes returning to the surface from a particular depth interval. The lighter shaded elements on gray scale typically denote subsurface features that reflect significant amounts of radar energy. As shown in these figures, the lighter shaded elements with linear trends are indicative of buried drain lines in an agricultural farm (Chow and Rees, 1989)

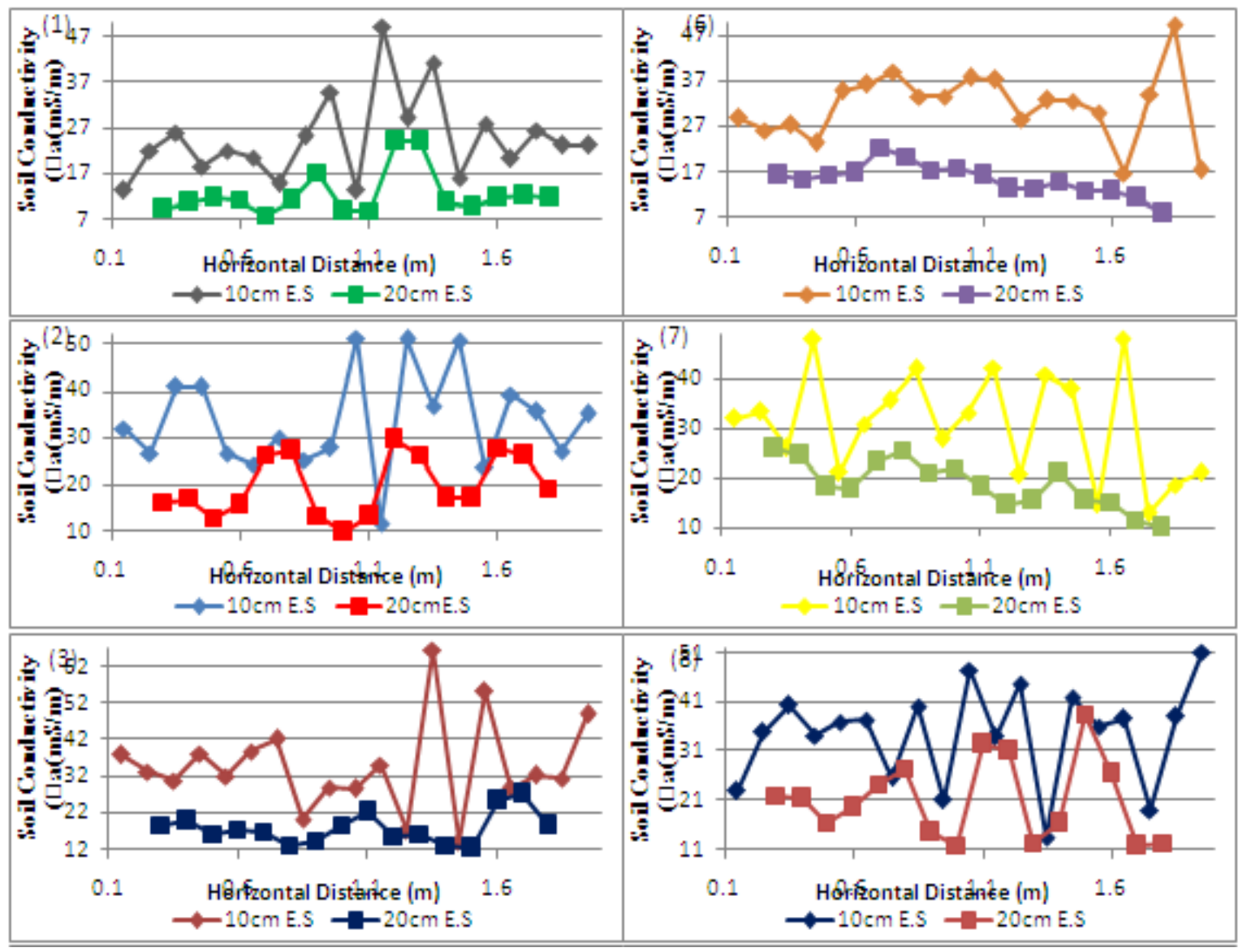



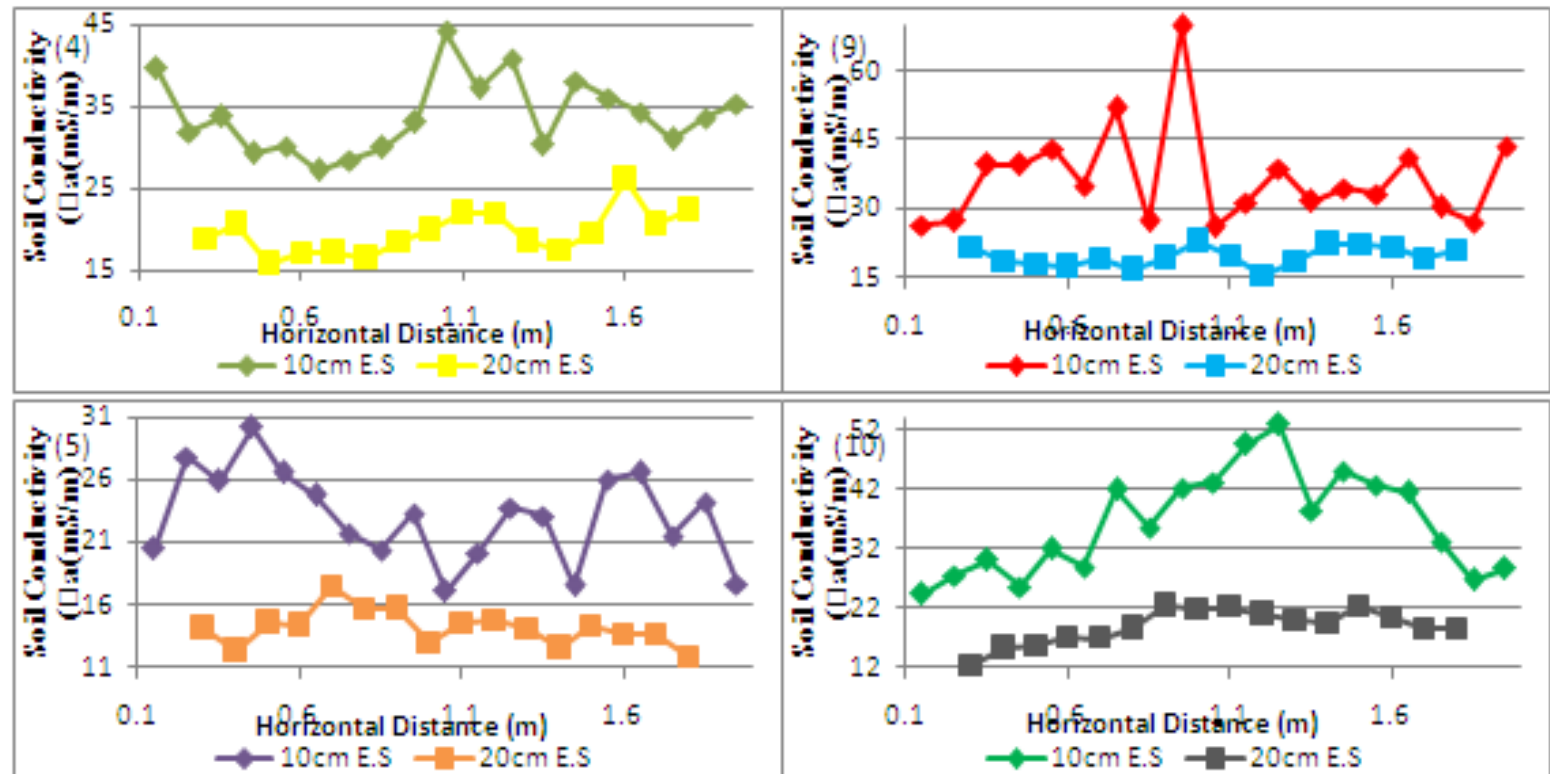

Fig. 10: Graph of Soil Conductivity against Horizontal Distance for $10 \mathrm{~cm}$ and $20 \mathrm{~cm}$ electrode spacing from

Profile 1 to 10 for the fourth measurement taken from the Box ten weeks after planting of maize.

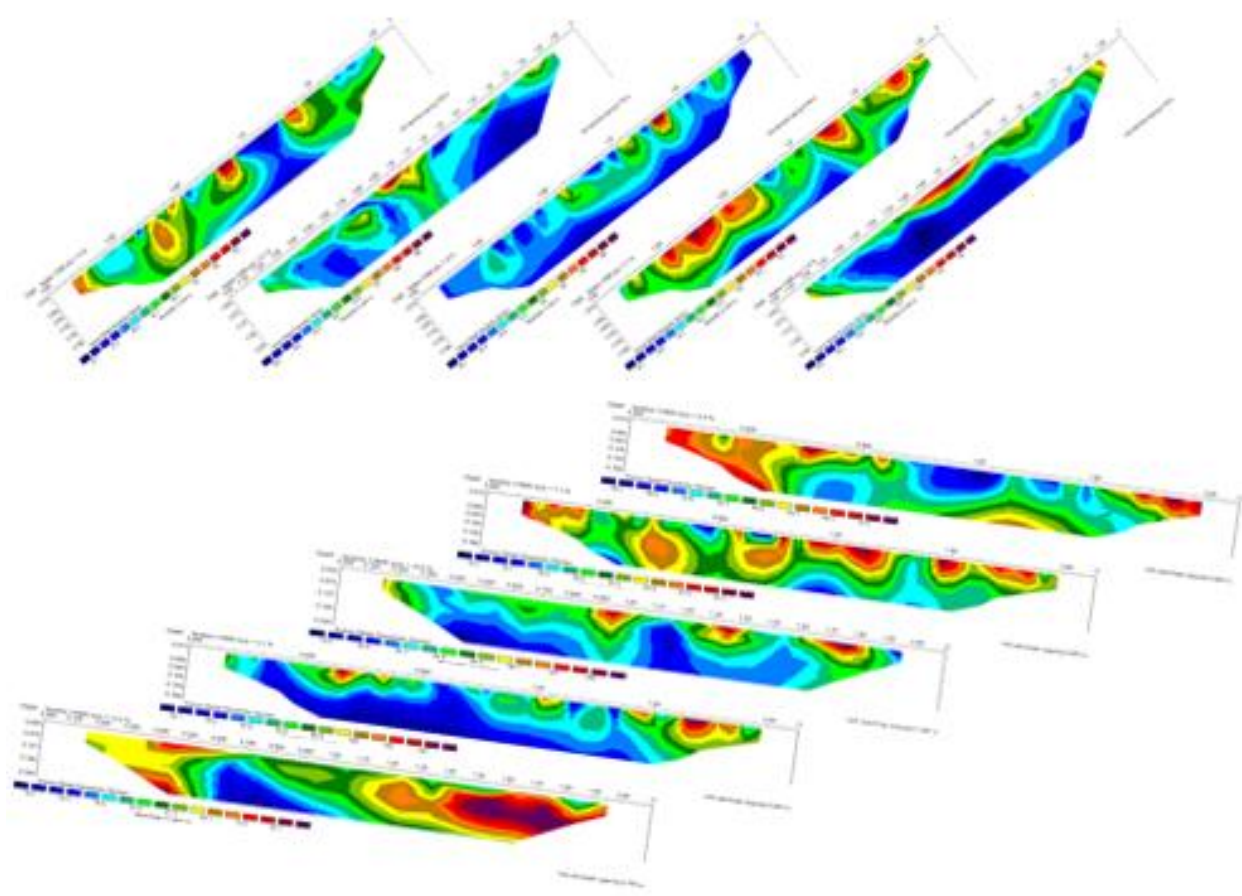

Fig. 11: Stacked 2-D inverted section for measurements taken tenth week of planting

Table 2: Growth Rate (height in $\mathrm{cm}$ ) of planted maize- tenth week after planting

\begin{tabular}{|l|l|l|l|l|}
\hline $\begin{array}{l}\text { COLUMN } \\
\text { ROW }\end{array}$ & & & & \\
& & & & \\
\hline 1 & 1 & 2 & 3 & 4 \\
\hline 2 & $98 \mathrm{~cm}$ & $110 \mathrm{~cm}$ & $95 \mathrm{~cm}$ & $110 \mathrm{~cm}$ \\
\hline 3 & $120 \mathrm{~cm}$ & $85 \mathrm{~cm}$ & $85 \mathrm{~cm}$ & $140 \mathrm{~cm}$ \\
\hline 4 & $100 \mathrm{~cm}$ & $125 \mathrm{~cm}$ & $136 \mathrm{~cm}$ & $150 \mathrm{~cm}$ \\
\hline
\end{tabular}




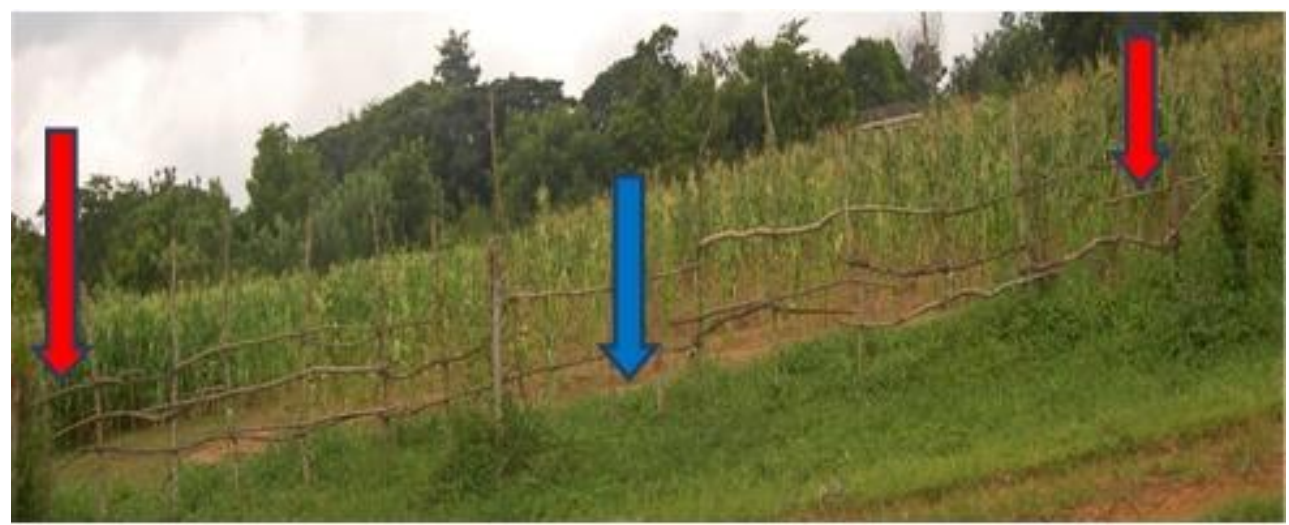

(a)

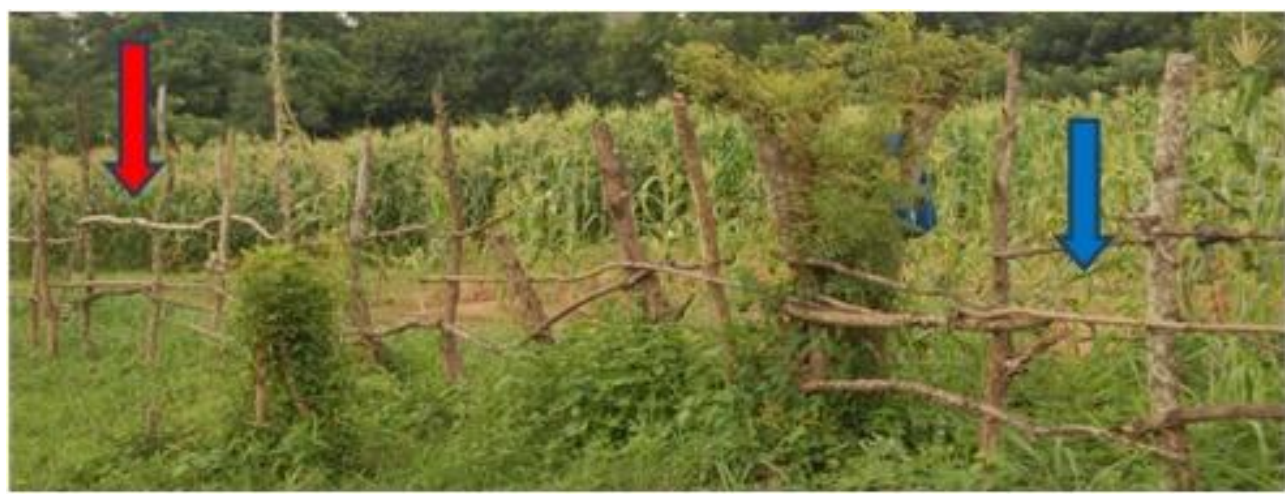

(b)

Fig. 12: Field examples of the effect of soil electrical conductivity on growth of plantedmaize

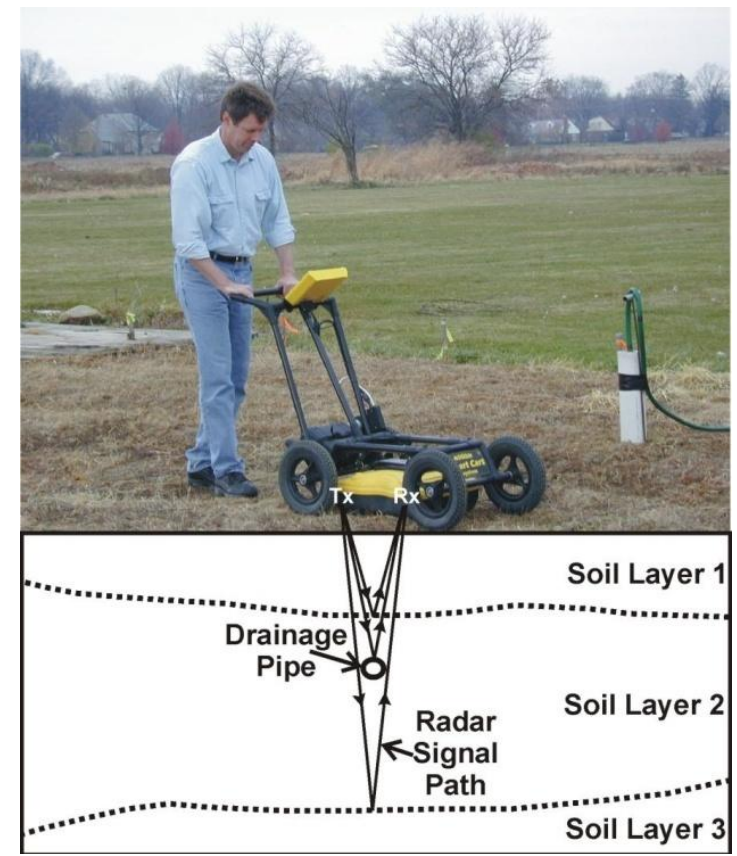

Fig. 13: Ground Penetrating Radar Principles of Operation 


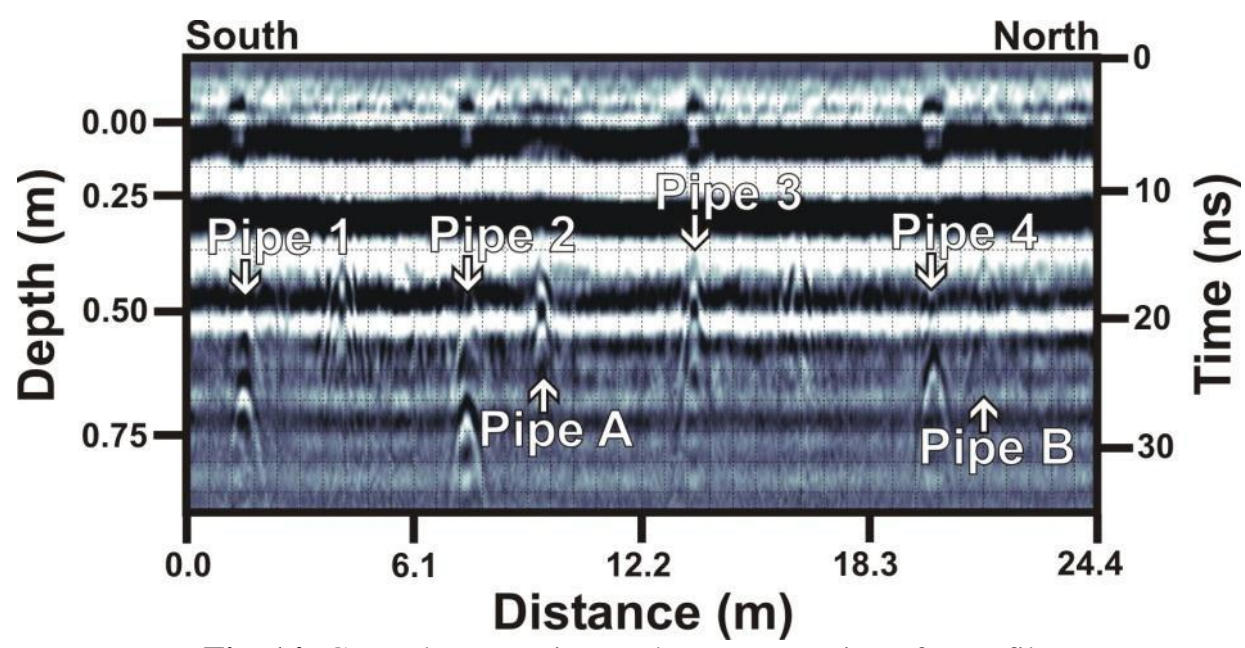

Fig. 14: Ground Penetrating Radar Interpretation of a Profile

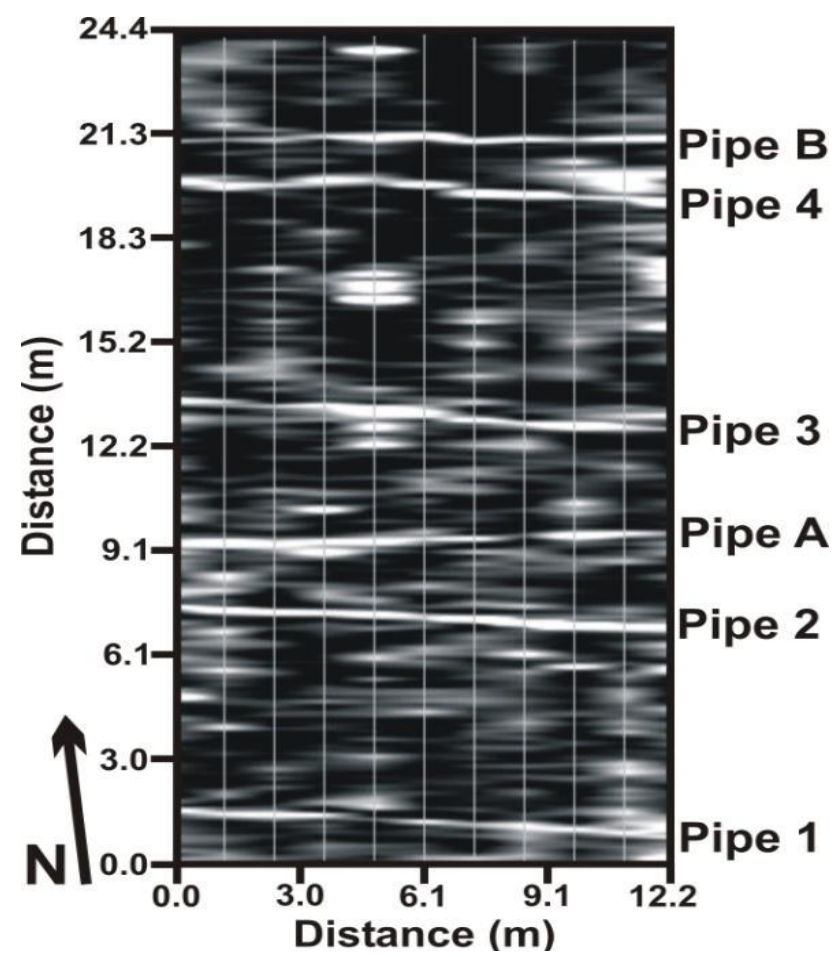

Fig. 15: Ground Penetrating Radar Map of the farm

\section{Conclusion}

Adequate irrigation planning and management can have beneficial effects on many crops. There will be potentially less agrochemicals and sediment released offsite via subsurface drainage and surface runoff, hence; adverse environmental impacts on local waterways are diminished. Geophysical methods can be applied in understanding the subsurface water flow patterns and help monitor the soil suitability for maximum agricultural production.

Farmers practicing precision agriculture can now access detailed information about the spatial characteristics of the soil they operate on. Farming becomes easier because application of geophysical methods can now provide needed operational guide concerning what can be obtainable on a site and to what extent a piece of land can be maximized for agricultural use.

\section{References}

[1]. Allred, B.J., Groom, D., and Reza Ehsani, M., 2008, Resistivity methods: in Handbook of agricultural geophysics, Allred, B.J. (ed.), CRC Press, Boca Raton, FL.

[2]. Annan, A.P., 2002.Ground Penetrating Radar Workshop Notes.Sensors and Software Inc., PEMD 217, Ont., Canada.

[3]. Barry Allred andHamid Farahani,2012:Use of Geophysical Methods in Agriculture - Introduction.USDA/ARS - Soil Drainage Research UnitColumbus, $\mathrm{OH}$. In press. 
[4]. Bowling, S.D., Schulte, D.D., Woldt, W.E., 1997.A geophysical and geostatistical methodology for evaluating potential subsurface contamination from feedlot runoff retention ponds.ASAE Paper No. 972087. ASAE, St. Joseph, MI.

[5]. Cassidy, N.J. (2009). Electrical and magnetic properties of rocks, soils, and fluids, In: Ground Penetrating Radar: Theory and Applications, Jol, H.M., pp. 41-72, Elsevier, ISBN 978-0-444-53348-7, Amsterdam, The Netherlands.

[6]. Chow, T. L., and Rees, H.W., 1989: Identification of subsurface drain locations with Ground Penetrating Radar, Can. Jour. Soil Sci, Vol. 69, pp. $223-234$

[7]. Dalan, R.A., 1991. Defining archaeological features with electromagneticsurveys at the Cahokia Mounds State Historic Site.Geophysics 56 (8), 1280-1287.

[8]. Doolittle, J.A., Suddith, K.A., Kitchen, N.R., and Indorante, S.J., 1994: Estimating depths to claypans using electromagnetic induction methods, J. Soil Water Conserve. 49(6), 572-575.

[9]. Ezeoke, B. N., 2014: Laboratory experiment to determine the relationship between apparent electrical conductivity, water content and growth rate of maize. MPhil/PhD Dissertation, Department of Physics, University of Ibadan, pp $66-73$.

[10]. Garr'e, S., G“unther, T., Diels, J., and Vanderborght, J., 2012: Evaluating experimental design of ERT for soil moisture monitoring in contour hedgerow intercropping systems, Vadose Zone J., 11, 14 pp., doi:10.2136/vzj2011.0186,.

[11]. Jaynes, D.B., Colvin, T.S., Ambuel, J., 1993. Soil type and crop yield determinations from ground conductivity surveys. ASAE Paper No. 933552. ASAE, St. Joseph, MI.

[12]. Kovacs, A., Morey, R.M., 1991.Sounding sea ice thickness usinga portable electromagnetic induction instrument. In: Muggeridge,D.B., Colbourne, D.B., Muggeridge, H.M. (Eds.),11th International Conference on Port and Ocean EngineeringUnder Arctic Conditions, St. John's, Newfoundland, Canada.Ocean Engineering Research Centre, St. John's, NF, September1991, vol.I, pp. 324-343 (ISBN 088901-175-3).

[13]. Mankin, K.R., Ewing, K.L., Schrock, M.D., Kluitenberg, G.J.,1997. Field measurement and mapping of soil salinity in salineseeps. ASAE Paper No. 973145. ASAE, St. Joseph, MI.

[14]. Morgan, M,.and D. Ess. 1997. The Precision-Farming Guide for Agriculturists. John Deere Publishing. Moline, IL.

[15]. Nyquist, J.E., Blair, M.S., 1991. Geophysical tracking and datalogging system: description and case history. Geophysics 56(7), $1114-1121$.

[16]. Oladunjoye, M.A.,Adoro, S. O., and Eyinla D. S. 2014: Geo-electric imaging of a teaching research farm at Ajibode, Ibadan, Southwestern Nigeria. In press

[17]. Rhoades, J.D., and J. Loveday. 1990. Salinity in irrigated agriculture. p. 1089-1142. In B.A. Stewart and D.R. Nielsen (ed.) Irrigation of agricultural crops. Agron.Monogr. 30. ASA, CSSA, and SSSA, Madison, WI

[18]. Robinson, D. A., Jones, S. B., Wraith, J. M., Or, D., and Friedman, S. P., 2003: A review of advances in dielectric and electrical conductivity measurement in soils using time domain reflectometry, Vadose Zone J., 2, 444-475.

[19]. Robert "Bobby" Grisso, Mark Alley, David Holshouser, Wade Thomason 2009: Precision Farming Tools: Soil Electrical Conductivity. Virginia Cooperative Extensionpublication 442-508.

[20]. Sudduth, K.A., Kitchen, N.R., Hughes, D.F., and Drummond, S. T., 1995: Electro-magnetic induction sensing as an indicator of productivity on claypan soils. In: Robert, P.C., Rust, R. H., Larson, W. E. (Eds.) proceedings of the second international conference on site- specific management for Agricultural Systems. ASA-CSSA-SSSA, Madison, WI, USA, pp 671-681.

[21]. Topp, G.C., Davis, J.L., Annan, A.P., 1980. Electromagnetic determination of soil water content: measurements in coaxial transmission lines. Water Resource Research 16, 574-582.

[22]. Werban, U., Al Hagrey, S. A., and Rabbel, W., 2008: Monitoring of rootzone water content in the laboratory by 2D geoelectrical tomography, J. Plant Nutr. Soil Sc., 171, 927-935,. 